\title{
LEVEDURA MISTA (CERVEJA + CANA-DE-AÇÚCAR) SPRAY-DRY NA ALIMENTAÇÃO DE LEITÕES NA FASE INICIAL
}

\author{
MIXED SPRAY-DRY YEAST (BREWER + SUGAR CANE) ON STARTING PIGS FEEDING
}

\author{
Poveda Parra, A.R. ${ }^{*}$; Moreira, I. ${ }^{1}$; Furlan, A.C. ${ }^{1}$; Carvalho, P.L.O. ${ }^{1}$; Peñuela Sierra, L.M. ${ }^{1}$ \\ e Filho, C.C. ${ }^{1}$
}

'Departamento de Zootecnia.Universidade Estadual de Maringá. Maringá, PR.Brasil. *angelapovedaparra@ hotmail.com

\section{PalaVRAS ChaVE ADICIONAIS}

Alimento protéico. Subproduto. Valor nutricional.

\section{RESUMO}

Foram conduzidos três experimentos para determinar o valor nutricional das leveduras spraydry cana-de-açúcar (LEV35) e levedura mista (cerveja + cana-de-açúcar - LEV40) e o efeito da inclusão da LEV40 em rações para leitões sobre o desempenho e viabilidade econômica. No ensaio de digestibilidade total foram utilizados 15 leitões machos castrados, com $21,49 \pm 4,85 \mathrm{~kg}$ de peso vivo, distribuídos em delineamento inteiramente casualizado. Os valores de energias digestível e metabolizável na matéria natural para a LEV35 e LEV40 foram de 2788 e 3455 (kcal $/ \mathrm{kg}) ; 2761$ e $3289(\mathrm{kcal} / \mathrm{kg})$, respectivamente. No primeiro ensaio de desempenho foram avaliados cinco níveis de inclusão da LEV40 (0, 5, 10, 15 e $20 \%$ ) na forma farelada, utilizando 50 leitões, com peso inicial de $14,60 \pm 1,28 \mathrm{~kg}$, distribuídos em delineamento de blocos inteiramente casualizado. No segundo ensaio de desempenho foram avaliados os cinco níveis de inclusão utilizados no ensaio anterior nas formas farelada ou peletizada, utilizando 80 leitões, com peso inicial de $15,16 \pm 2,00 \mathrm{~kg}$, distribuídos em delineamento inteiramente casualizado em esquema fatorial $5 \times 2$. Os resultados indicam que a inclusão de até $20 \%$ da LEV40 em rações para leitões nas duas formas não afeta o desempenho. Entretanto, a viabilidade econômica vai depender da relação de preços entre os ingredientes.

\section{SUMMARY}

Three experiments were carried out to deter-

\author{
AdDitionAL KEYWORDS \\ Co-product. Nutritional value. Protein feedstuffs.
}

mine the nutritional values of the spray-dry yeast sugar cane (LEV35) and mixed (brewer + sugar cane-LEV40) and the inclusion effect on starting pigs diets on performance and economic feasibility. In total digestibility assays were used fifteen barrow pigs with initial body weight of $21.49 \pm 4.85$ $\mathrm{kg}$ were allotted in a completely randomized design. The values of digestible and metabolizable energy as-fed basis for LEV35 and LEV40 were: 2788 and $3455(\mathrm{kcal} / \mathrm{kg}) ; 2761$ and $3289(\mathrm{kcal} / \mathrm{kg})$, respectively. In performance trial were evaluated five inclusions levels of $\operatorname{LEV} 40(0,5,10,15$ and $20 \%$ ) utilizing 50 piglets, with initial weight of $14.60 \pm 1.28 \mathrm{~kg}$ in meal form, distributed in a completely randomized bloc design. In second performance trial were evaluated five inclusions levels of previous assay in meal form or pellet form, using 80 piglets, with initial weight of $15.16 \pm 2.00 \mathrm{~kg}$, allotted in a completely randomized factorial $5 \times 2$. The results indicate that the inclusion of up to $20 \%$ of LEV 40 in diets for piglets in the two forms did not affect performance. However, the economic feasibility will depend on the price relationship between the ingredients.

\section{INTRODUÇÃO}

As frequentes oscilações nos preços do milho e farelo de soja, principais componentes das rações de suínos no Brasil, estimulam a busca por ingredientes alternativos. Ingredientes de origem vegetal processados 


\section{POVEDA PARRA, MOREIRA, FURLAN, CARVALHO, PEÑUELA SIERRA E FILHO}

têm sido utilizados como fonte energética ou proteica nas dietas de leitões (Bertol et al., 2000), entre eles está a levedura seca (Saccharomyces spp), indicada como alternativa em substituição parcial ao farelo de soja (Moreira et al., 2002; Castillo et al. 2004; Araújo et al, 2006; Junqueira et al., 2008).

A levedura obtida da indústria sucroalcooleira é um alimento protéico proveniente da fermentação anaeróbia do caldo de cana ou do melaço. A secagem pelo método de spray-dry, resulta em um produto de melhor qualidade em função da menor exposição às altas temperaturas (Moreira, J.A. et al., 1998; Zanutto et al., 1999). Neste processo de secagem, são preservadas as vitaminas do complexo B, principalmente, tiamina, riboflavina, niacina e ácido pantotênico (Furuya et al., 2000). No Brasil, usa-se a levedura de cana-de-açúcar (seca por spray-dry) proveniente da produção de álcool de cana-de-açúcar, entretanto, recentemente, tem sido disponibilizado um composto misto de levedura de cana-deaçúcar + levedura de cervejaria. Por ser novo no mercado, este produto não foi devidamente estudado e as informações sobre o uso como alternativa na alimentação de suínos é limitada.

As rações oferecidas aos leitões na fase inicial podem ser na forma farelada, sendo esta a mais utilizada por ser mais econômica e trazer resultados zootécnicos satisfatórios, ou na forma peletizada a qual melhora o consumo de ração, o ganho diário de peso, a conversão alimentar e diminui a formação de pó e reduz desperdícios (Moreira et al., 1995).

Assim, objetivou-se, com este trabalho, determinar o valor nutricional das leveduras spray-dry (cana-de-açúcar-LEV35 e levedura mista (cerveja + cana-de-açúcar-LEV40), por meio de estudo de digestibilidade e verificar os efeitos da inclusão da LEV40 em rações para leitões na fase inicial $(15-30 \mathrm{~kg})$ sobre o desempenho e a viabilidade econômica.

\section{MATERIALE MÉTODOS}

Os experimentos foram realizados no Setor de Suinocultura da Fazenda Experimental de Iguatemi (FEI), da Universidade Estadual de Maringá, localizado no estado do Paraná $\left(23^{\circ} 21^{\prime} \mathrm{S}, 52^{\circ} 04^{\prime} \mathrm{W}\right.$, a uma altitude de 564 metros).

No ensaio de digestibilidade foram utilizados 15 suínos machos castrados com peso inicial de $21,49 \pm 4,85 \mathrm{~kg}$. Os animais foram alojados individualmente em gaiolas de metabolismo, em sala com temperatura parcialmente controlada $\left(24^{\circ} \mathrm{C}\right)$, por meio de equipamentos de ar condicionado.

A ração referência foi composta principalmente por milho e farelo de soja, foi calculada para atender as exigências indicadas no NRC (1998). A ração referência foi composta por milho $(69,51 \%)$, farelo de soja $(26,95 \%)$, óleo de soja $(0,24 \%)$, calcário $(0,64 \%)$, fosfato bicálcico $(1,49 \%)$, sal comum $(0,52 \%)$, suplemento vitamínico mineral $(0,65 \%)$. Os ingredientes testados foram a LEV35 e LEV40 que substituíram, com base na matéria seca, $25 \%$ da ração referência, resultando em duas rações teste (RT). O período experimental durou 17 dias (12 dias de adaptação às gaiolas e a ração e cinco de coleta total de fezes e urina). $\mathrm{O}$ delineamento experimental foi o inteiramente casualizado, com três tratamentos, cinco repetições, e a unidade experimental constituída por um suíno.

Foi adotada a metodologia de coleta total e o $\mathrm{Fe}_{2} \mathrm{O}_{3}(2 \%)$ foi usado como marcador fecal no início e final das coletas. As fezes totais produzidas foram coletadas uma vez ao dia, acondicionadas em sacos plásticos e armazenadas em congelador a -18 ${ }^{\circ} \mathrm{C}$. Posteriormente, o material foi homogeneizado, seco em estufa de ventilação forçada $\left(55^{\circ} \mathrm{C}\right)$ e moído em moinho tipo martelo (criva de $1 \mathrm{~mm}$ ) para a realização de análises laboratoriais. A urina foi coletada em baldes plásticos, contendo $20 \mathrm{~mL}$ de $\mathrm{HCl}$ 1:1 para evitar a proliferação bacteriana e possíveis perdas por volatilização. 


\section{LEVEDURA MISTA SPRAY-DRY NA ALIMENTAÇÃO DE LEITÕES}

As análises das rações e das fezes foram realizadas segundo os procedimentos descritos por Silva e Queiroz (2002). Os valores de energia bruta foram determinados por meio de calorímetro adiabático (Parr Instrument Co.). Os coeficientes de digestibilidade da matéria seca (CDMS), energia bruta (CDEB), proteína bruta (CDPB) e matéria orgânica (CDMO) foram calculados conforme Moreira et al. (1994). Aplicou-se a fórmula de Matterson et al. (1965) para a obtenção dos nutrientes digestíveis das duas leveduras spray-dry.

Para avaliar as diferenças entre os coeficientes de digestibilidade da LEV35 e LEV40, os dados foram submetidos à análise de variância, utilizando o pacote estatístico SAEG(UFV, 1997), de acordo com o seguinte modelo estatístico:

$Y_{i j}=\mu+T_{i}+e_{i j}$

em que:

$Y_{i j}=$ coeficientes de digestibilidade do tratamento i, da repetição j;

$\mu=$ constante associada a todas as observações; $\mathrm{T}_{\mathrm{i}}=$ efeito do tipo do alimento $\mathrm{i}$, sendo $\mathrm{i}=1 ; 2(1=$ LEV35 e 2 = LEV40);

$\mathrm{e}_{\mathrm{ij}}=$ erro aleatório associado a cada observação.

No primeiro ensaio de desempenho (ensaio I) foram utilizados 25 machos e 25 fêmeas, híbridos comerciais, com peso inicial de $14,60 \pm 1,28 \mathrm{~kg}$ e final de $31,36 \pm 3,82$ $\mathrm{kg}$. O experimento foi realizado no período de março a maio de 2008 e as temperaturas médias registradas no período experimental foram de $16,99 \pm 3,56^{\circ} \mathrm{C}$ mínimae $26,8 \pm 4,3^{\circ} \mathrm{C}$ máxima.

Os animais (dois por baia) foram alojados em galpão de creche, em baias $\left(1,32 \mathrm{~m}^{2}\right)$ elevadas, com comedouros semiautomáticos e bebedouros tipo chupeta. As rações e água foram fornecidas à vontade durante todo o período experimental.

Os tratamentos consistiam de cinco rações com níveis crescentes de inclusão $(0,5,10,15$ e $20 \%)$ da levedura spray-dry mista (cerveja + cana-de-açúcar, LEV40).
As rações à base de milho e farelo de soja (tabela I) foram formuladas para atender as exigências recomendadas pelo NRC (1998) para suínos na fase inicial. Foram adicionados aminoácidos sintéticos (L-lisina, DLmetionina, L-treonina e L-triptofano) para atender ao padrão de proteína ideal (tabela I), conforme o indicado pelo NRC (1998). Para os cálculos foi utilizada a composição química e energética da LEV40 obtida no experimento de digestibilidade (tabela II).

Os animais foram distribuídos em um delineamento de blocos (no tempo) inteiramente casualizado, com cinco níveis de inclusão da levedura $(0,5,10,15$ e $20 \%)$, cinco repetições e dois leitões por unidade experimental. Os animais foram pesados no início e no final do experimento, bem como o consumo total de ração computado ao final. Com estes dados foram calculados o consumo diário de ração (CDR), ganho diário de peso (GDP) e conversão alimentar (CA).

No início e no final do experimento foram colhidas amostras de sangue via veia cava cranial em tubos com heparina (Cai et al., 1994) para análise do nitrogênio da ureia plasmática (NUP). As amostras foram centrifugadas (3000 rpm por 15 minutos) para obtenção do plasma, que foi transferido para microtubos de $1,5 \mathrm{~mL}$ os quais foram devidamente identificados e armazenados em freezer $\left(-18^{\circ} \mathrm{C}\right)$ para posteriores análises. Os valores de NUP foram determinados pelo método de Marsh et al. (1965). Os resultados do NUP inicial foram utilizados como covariável para a análise estatística do NUP final.

Para avaliar a viabilidade econômica da levedura mista spray-dry foram cotados os preços das matérias-primas no mercado local e calculado o custo da ração por quilograma de peso vivo ganho, segundo Bellaver et al. (1985) conforme descrito:

$Y_{i}(R \$ / k g)=Q_{i} \times P_{i} / G$

em que:

$Y_{i}=$ custo da ração por $\mathrm{kg}$ de peso vivo ganho no 


\section{POVEDA PARRA, MOREIRA, FURLAN, CARVALHO, PEÑUELA SIERRA E FILHO}

Tabela I. Composição centesimal, energética e química das rações, contendo diferentes níveis de inclusão da levedura mista spray-dry (LEV40) para leitóes na fase inicial (15-30 $\mathrm{kg}$ ). (Ingredients, energy and chemical composition of diets containing different levels of inclusion of mixed spray dry yeast (LEV40) in starting (15-30 kg) pigs).

\begin{tabular}{|c|c|c|c|c|c|}
\hline & & Níveis & clusão & V40, \% & \\
\hline & 0 & 5 & 10 & 15 & 20 \\
\hline Milho & 73,08 & 70,38 & 69,71 & 70,96 & 72,21 \\
\hline Levadura mista spray-dry (LEV-40) & - & 5,00 & 10,00 & 15,00 & 20,0 \\
\hline Farelo de soja & 22,76 & 20,69 & 16,44 & 10,14 & 3,83 \\
\hline Óleo de soja & 0,43 & 0,40 & 0,37 & 0,34 & 0,31 \\
\hline Calcário & 0,64 & 0,65 & 0,66 & 0,67 & 0,68 \\
\hline Fosfato bicálcico & 1,63 & 1,60 & 1,59 & 1,59 & 1,59 \\
\hline Sal comum & 0,40 & 0,40 & 0,40 & 0,40 & 0,40 \\
\hline Suplemento vitamininico e mineral ${ }^{1}$ & 0,50 & 0,50 & 0,50 & 0,50 & 0,50 \\
\hline Leucomag (Leucomicina, 30 \%) & 0,05 & 0,05 & 0,05 & 0,05 & 0,05 \\
\hline L-Lisina $\mathrm{HCl}, 99 \%$ & 0,36 & 0,26 & 0,23 & 0,26 & 0,30 \\
\hline DL- Metionina, $99 \%$ & 0,06 & 0,04 & 0,04 & 0,06 & 0,07 \\
\hline L-Treonina, 98,5 \% & 0,09 & 0,03 & - & - & - \\
\hline L-Triptofano, $98 \%$ & - & - & 0,01 & 0,03 & 0,06 \\
\hline Valores calculados ${ }^{2}$ & & & & & \\
\hline Energía digestível, Mcal/kg & 3,36 & 3,36 & 3,36 & 3,36 & 3,36 \\
\hline Lisina digestível, \% & 0,99 & 0,99 & 0,99 & 0,99 & 0,99 \\
\hline Metionina+cistina digestível, \% & 0,55 & 0,55 & 0,55 & 0,55 & 0,55 \\
\hline Treonina digestível, \% & 0,62 & 0,62 & 0,62 & 0,62 & 0,62 \\
\hline Triptofano digestível, \% & 0,17 & 0,17 & 0,17 & 0,17 & 0,17 \\
\hline Cálcio, \% & 0,72 & 0,72 & 0,72 & 0,72 & 0,72 \\
\hline Fósforo total, \% & 0,60 & 0,60 & 0,60 & 0,60 & 0,60 \\
\hline
\end{tabular}

${ }^{1}$ Conteúdo/kg de produto: vit. A: 2000000 UI; vit. D3: 400000 UI; vit. E: 5000 UI; vit. K3: 400 mg; vit. B12: $6000 \mathrm{mcg}$; vit. B2: $1200 \mathrm{mg}$; biotina: 20 g; ac. pantotênico: $2400 \mathrm{mg}$; ac. nicotínico: $6000 \mathrm{mg}$; colina: 30 g; antioxidante: $20000 \mathrm{mg}$; vit. B1: $400 \mathrm{mg}$; vit. B6: $600 \mathrm{mg}$; ácido fólico: $200 \mathrm{mg}$; Cu: $35 \mathrm{~g}$; Zn: 20 g; Co: 200 mg; Mn: 8 g; Fe: 20 g; I: 300 mg; veículo: q.s.p. 1000 g; ${ }^{2 B a s e ~ n a ~ c o m p o s i c ̧ a ̃ o ~ d o s ~ a l i m e n t o s ~ i n d i c a d o s ~}$ por Rostagno et al. (2005) e de análises realizadas no LANA-UEM, bem como tabela II (ensaio I).

i-enésimo tratamento;

$\mathrm{Q}_{\mathrm{i}}=$ quantidade de ração consumida no i-enésimo tratamento;

$P_{i}=$ preço por $k g$ da ração utilizada no i-enésimo tratamento;

$G_{i}=$ ganho de peso no i enésimo tratamento.

Oíndice de eficiência econômica (IEE) e o índice de custo (IC) foram calculados segundo a metodologia proposta por Gomes etal. (1991).

IEE $(\%)=\mathrm{MCe} / \mathrm{CTei} \times 100$

IC $(\%)=$ CTei/ MCe $\times 100$ em que:

$\mathrm{MCe}=$ menor custo da ração por kg ganho observado entre os tratamentos;

Ctei $=$ custo do tratamento i considerado.

Os preços dos insumos foram utilizados para calcular os custos das rações experimentais. Os preços dos insumos foram utilizados para calcular os custos das rações experimentais. O milho custou $\mathrm{R} \$ 0,32 / \mathrm{kg}^{1}$, o farelo de soja $\mathrm{R} \$ 0,76 / \mathrm{kg}$, o óleo de soja R\$ $2,28 / \mathrm{kg}$ e a levedura de cerveja + cana-de-

$\overline{{ }^{1} 1 \mathrm{R} \$=} 0,56 \mathrm{US} \$$.

Archivos de zootecnia vol. 62, núm. 238, p. 202. 


\section{LEVEDURA MISTA SPRAY-DRY NA ALIMENTAÇÃO DE LEITÕES}

Tabela II. Composição química, energética (matéria natural), coeficientes de digestibilidade $(C D)$ e valores digestíveis das leveduras spray-dry LEV35 e LEV40 (matéria natural) para leitões na fase inicial (15-30 $\mathrm{kg}$ ). (Chemical and energy (as fed basis) composition, digestibility coefficients (CD) and digestible values of spray dry yeast LEV35 and LEV40 (as fed basis) for starting (15-30 kg) pigs).

\begin{tabular}{lcc}
\hline & LEV35 & LEV40 \\
\hline Matéria seca, \% & 94,52 & 92,94 \\
Proteína bruta, \% & 33,6 & 37,6 \\
Lisina, \% & 2,77 & 2,72 \\
Metionina+cistina, \% & 1,12 & 1,08 \\
Treonina, \% & 2,04 & 1,99 \\
Triptofano, \% & 0,14 & 0,29 \\
Cálcio, \% & 0,04 & 0,19 \\
Fósforo total, \% & 0,55 & 0,63 \\
Matéria mineral, \% & 3,11 & 5,83 \\
Matéria orgânica \% & 91,41 & 87,11 \\
Energia bruta, kcal/kg & 4218 & 4182 \\
& & \\
Coeficientes, \% & & \\
CD da matéria seca & $76,72^{\mathrm{b}}$ & $87,27^{\mathrm{a}}$ \\
CD da energia bruta & $66,08^{\mathrm{b}}$ & $82,65^{\mathrm{a}}$ \\
CD da proteína bruta & $78,97^{\mathrm{b}}$ & $93,21^{\mathrm{a}}$ \\
CD da matéria orgânica & $91,18^{\mathrm{b}}$ & $88,69^{\underline{a}}$ \\
& & \\
Valores digestíveis & & \\
Matéria seca digestível, \% & 72,51 & 81,11 \\
Energia digestível, kcal/kg & 2788 & 3455 \\
Energia metabolizável, kcal/kg & 2761 & 3289 \\
Proteína digestível, \% & 25,54 & 33,02 \\
Matéria orgânica digestível, \% 86,18 & 82,43 \\
\hline
\end{tabular}

abMédias seguidas de letras minúsculas diferentes na linha, diferem $(p<0,05)$ pelo teste $F$.

açúcar spray-dry $\mathrm{R} \$ 1,10 / \mathrm{kg}$.

Os resultados foram submetidos à análise de regressão polinomial de acordo com o seguinte modelo estatístico:

$\mathrm{Y}_{\mathrm{ij}}=\mu+\mathrm{b} 1(\mathrm{Ni}-\mathrm{N})+\mathrm{b} 2(\mathrm{Ni}-\mathrm{N})+\mathrm{e}_{\mathrm{ij}}$

em que:

$Y_{i j}=$ valor observado das variáveis estudadas, relativo a cada individuo j, recebendo o nível i de LEV40; $\mu=$ constante geral;

b1 = coeficiente de regressão linear do nível de LEV40 sobre a variável Y;

b2 = coeficiente de regressão quadrático do nível de LEV40 sobre a variável Y;

$\mathrm{Ni}=$ níveis de $L E V 40$ nas rações, sendo $i=0,5,10$, 15 e $20 \%$;

$\mathrm{N}=$ nível médio de LEV40 nas rações;

$\mathrm{e}_{\mathrm{ij}}=$ erro aleatório associado a cada observação.

Para a comparação dos resultados da ração testemunha (sem inclusão de LEV40) com cada um dos níveis de inclusão da levedura mista, foi aplicado o teste de Dunnet (Sampaio, 1998). As análises estatísticas foram efetuadas utilizando o pacote estatístico SAEG.

Como foi verificado no ensaio I que os níveis de inclusão da LEV40 não influenciaram as variáveis estudadas, foi conduzido o ensaio II para verificar se o processo de peletização melhoraria as respostas dos níveis mais elevados da LEV40.

Neste segundo experimento de desempenho foram utilizados 40 machos e 40 fêmeas, com peso inicial de $15,16 \pm 1,36 \mathrm{~kg}$ e final $30,72 \pm 2,72 \mathrm{~kg}$. Os animais foram alojados em galpão de creche, conforme o descrito anteriormente no ensaio II. Os animais foram distribuídos em um delineamento inteiramente casualizado em esquema fatorial $5 \times 2$, sendo cinco níveis de inclusão de LEV40 $(0,5,10,15$ e $20 \%)$ e duas formas (farelada ou peletizada), com quatro repetições e dois leitões por unidade experimental.

A composição das rações experimentais (tabela I) bem como os demais procedimentos experimentais foram os mesmos utilizados no ensaio II.

Os resultados foram submetidos à análise de variância, utilizando o pacote estatístico SAEG, adotando-se o seguinte modelo estatístico:

$Y_{i j k}=\mu+B_{i}+N_{j}+F_{k}+N F_{j k}+e_{i j k l}$

em que:

$Y_{\mathrm{ijk}}=$ observação do animal I, i, nível de inclusão 


\section{POVEDA PARRA, MOREIRA, FURLAN, CARVALHO, PEÑUELA SIERRA E FILHO}

j e da forma k;

$\mu=$ constante associada a todas as observações; $B_{i}=$ efeito do bloco, sendo $i=1,2,3,4$;

$\mathrm{N}_{\mathrm{j}}=$ efeito dos níveis de LEV40, sendo $\mathrm{j}=0,5,10$, $15,20 \%$;

$\mathrm{F}_{\mathrm{k}}=$ efeito da forma, sendo $\mathrm{k}$ = farelada e peletizada;

$\mathrm{NF}_{\mathrm{jk}}=$ efeito da interação dos níveis de inclusão $\mathrm{j}$ com a forma k;

$\mathrm{e}_{\mathrm{ijkl}}=$ erro aleatório associado a todas as observações.

\section{RESULTADOSEDISCUSSÃO}

A levedura de cana-de-açúcar (LEV35) apresentou, de forma geral conteúdo de nutrientes inferior (tabela II) aos encontrados por Miyada et al. (1992) e Moreira, I. et al. (1998) que estudaram respectivamente a levedura seca e a levedura de recuperação seca por spray-dry, como ingrediente de rações de leitões. Estes autores encontraram valores superiores para o fósforo 1,23 e $0,67 \%$, o cálcio 0,23 e $1,35 \%$ e para a matéria mineral 10,14 e 12,17\%, respectivamente.

A composição química da LEV35 apresentou valores superiores aos apresentados por Rostagno et al. (2005) para matéria seca $(90,85 \%)$, energia bruta (4157 kcal $/ \mathrm{kg})$ e inferiores para proteína bruta $(36,75 \%)$, cálcio $(0,29 \%)$, fósforo $(0,82)$ e energia metabolizável (3370). Os valores apresentados por Brum et al. (1999) foram inferiores para matéria seca $(90,28 \%)$, proteína bruta $(32,02 \%)$ e energia bruta $(3932 \mathrm{kcal} / \mathrm{kg})$ e superiores para cálcio $(0,15 \%)$ e fósforo $(1,02 \%)$. Os valores da LEV 35 foram inferiores aos encontrados por Zanutto et al. (1999) para a matéria seca $(96,0 \%)$, proteína bruta $(35,27 \%)$ e cálcio $(0,47 \%)$, porém foi superior para o fósforo $(0,42 \%)$ e para a energia metabolizável (3139 kcal $/ \mathrm{kg})$ e semelhante para energia bruta $(4283 \mathrm{kcal} / \mathrm{kg})$.

As variações nos valores da composição química da levedura de cana-de-açúcar, podem ser explicados pela variação do clima e cultivares. Além disso, a levedura pode ser obtida em diversas condições de processamento e manejo, o que pode afetar também sua composição (Generoso et al., 2008).
Por ser um produto novo no mercado brasileiro, não foram encontrados dados na literatura para a LEV40, porém comparando com os valores apresentados por Rostagno et al. (2005) para a levedura de cana-deacucar e para a levedura de cerveja foi observado que a LEV 40 apresentou valores superiores para a matéria seca $(92,94 \%)$, calcio $(0,19 \%)$, matéria mineral $(12,89 \%)$ e materia orgânica $(87,11 \%)$, entretanto, o valor do fosforo $(0,63 \%)$ foi inferior. Os valores de energia bruta e proteina bruta da LEV40 difierem dos apresentados por Rostagno et al. (2005) para as leveduras.

Os coeficientes de digestibilidade das duas leveduras spray-dry (tabela II) foram diferentes $(p<0,05)$, sendo que a LEV35 apresentou coeficientes de digestibilidade menores que a LEV40. Os coeficientes de digestibilidade da matéria seca e da energia bruta da LEV 35 foram inferiores aos encontrados por Zanutto et al. (1999). Por outro lado a LEV40 apresentou coeficiente de digestibilidade da matéria seca superior e da energia bruta inferior aos resultados de Albuquerque et al. (2011).

O coeficiente de digestibilidade da proteína bruta da LEV 35 foi baixo comparado a LEV40 (93,21\%). Segundo Yamada et al. (2003) a baixa digestibilidade proteica da levedura de cana-de-açúcar pode ser atribuída à resistência da parede celular à ação das enzimas digestivas, provavelmente seja esse o fator que as tornam mais espessas, dificultando a proteólise. A digestibilidade aparente da proteína na LEV40, cuja composição é a combinação da cana-de-açúcar e cerveja, foi superior ao valor encontrado por Albuquerque et al. (2011) quando avaliaram resíduo seco de cervejaria.

O valor de matéria seca digestível, energia digestível e energia metabolizável da LEV 35 foram inferiores aos encontrados por Zanutto et al. (1999) para levedura semelhante à LEV35.

No ensaio de desempenho (ensaio I) o consumo diário de ração e o ganho de peso 


\section{LEVEDURA MISTA SPRAY-DRY NA ALIMENTAÇÃO DE LEITÕES}

diário (tabela III) não foram diferentes ( $>>0,05)$ para as duas leveduras. Castillo et al. (2004) avaliaram o efeito da substituição $(0,25,50,75$ e $100 \%)$ do farelo de soja pela levedura desidratada por spray-dry como fonte protéica sobre o desempenho e observaram efeito quadrático para o CDR, sendo maior com 41,18\% de substituição da proteína bruta do farelo de soja pela proteína bruta da levedura.

A conversão alimentar apresentou piora linear $(\mathrm{p}<0,04)$ com a inclusão de LEV40 (tabela III), indicando que a LEV40 teve efeito prejudicial sobre a eficiência de uso das rações. Resultados semelhante foi observado por Moreira et al. (1996) onde observaram uma pior conversão, sem contudo, prejudicar o consumo. Araújo et al. (2006) avaliando três níveis de inclusão de levedura $(5,10$ e $15 \%)$ e Junqueira et al. (2008) que avaliaram o efeito de diferentes fontes proteica ( $10 \%$ de levedura) em rações para leitões não observaram diferenças nas variáveis de desempenho. Porém, Spark et al.(2005) avaliando, 20, 40 e $60 \%$ de levedura em substituição à soja, observaram um aumento no consumo das rações que continham levedura e ainda concluíram que com $40 \%$ de inclusão da levedura foi observado um aumento no ganho de peso e melhora na conversão alimentar, os autores atribuem estes resultados à palatabilidade das rações.

O NUP (tabela III) foi influenciado de forma quadrática $(\mathrm{NUP}=10,0727+0,414903 \mathrm{X}$ - 0,0299719X ${ }^{2}$ ) pela inclusão da LEV40, o que pode indicar maior desequilíbrio de aminoácidos e menor eficiência da utilização do N com o nível de $6,92 \%$ de inclusão de LEV40.

Tabela III. Desempenho (consumo diário de ração - CDR; ganho diário de peso - GDP e conversão alimentar - CA), nitrogênio da uréia plasmática (NUP) e analise econômica da ração (custo do quilograma de ração - CR; custo da ração por quilograma de peso vivo ganho; índice de eficiência econômica - IEE; índice de custo - IC) de leitões dos 15 a $30 \mathrm{~kg}$ alimentados com dietas contendo LEV4O - ensaio I). (Performance (daily fed intake - CDR; daily weight gain - GDP and fed conversion - CA), plasma urea nitrogen (NUP) and economic analysis of fed (diet cost kg - CR; feed cost per kilogram body weight gain; economic efficiency index - IEE; index costIC) of piglets from 15 to $30 \mathrm{~kg}$ fed diets containg LEV40- assay I).

\begin{tabular}{|c|c|c|c|c|c|c|c|c|}
\hline \multicolumn{9}{|c|}{ Níveis de inclusão da LEV40 (\%) } \\
\hline & 0 & 5 & 10 & 15 & 20 & CV (\%) & Dunn & Reg \\
\hline $\operatorname{CDR}(\mathrm{kg})$ & 1,188 & 1,266 & 1,234 & 1,281 & 1,345 & 13,36 & NS & NS \\
\hline GDP $(\mathrm{kg})$ & 0,590 & 0,609 & 0,594 & 0,596 & 0,579 & 15,45 & NS & NS \\
\hline $\mathrm{CA}$ & 2,008 & 2,081 & 2,123 & 2,175 & 2,339 & 11,39 & NS & $L=0,04$ \\
\hline $\mathrm{NUP}(\mathrm{mg} / \mathrm{dL})$ & 9,97 & 11,37 & 11,91 & 8,67 & 6,71 & 26,44 & NS & $\mathrm{Q}=0,05$ \\
\hline \multicolumn{9}{|l|}{ Analise econômica } \\
\hline $\mathrm{PI}(\mathrm{kg})$ & 14,48 & 14,77 & 14,62 & 14,63 & 14,53 & - & - & - \\
\hline $\mathrm{PF}(\mathrm{kg})$ & 31,20 & 31,86 & 31,49 & 31,28 & 30,96 & - & - & - \\
\hline $\mathrm{CR}(\mathrm{R} \$)$ & 0,64 & 0,66 & 0,68 & 0,72 & 0,77 & - & - & - \\
\hline $\mathrm{CR}(\mathrm{R} \$ / \mathrm{kg} \mathrm{PV}$ ganho $)$ & 1,29 & 1,37 & 1,44 & 1,57 & $1,80^{*}$ & 12,15 & 0,05 & $\mathrm{~L}=0,01$ \\
\hline IEE & 100,00 & 96,56 & 89,00 & 82,07 & 71,36 & - & - & - \\
\hline IC & 100,00 & 106,89 & 112,36 & 121,85 & 140,14 & - & - & - \\
\hline
\end{tabular}

Dunn= Teste de Dunnet; Reg= Análise de regressão. $L=$ Efeito linear: Conversão alimentar $=1,99452+$ 0,0151103X; $C R=1,24931+0,0244824 X ; Q=$ Efeito quadrático: $N U P=10,0727+0,414903 X-0,0299719 X^{2}$. *Valor diferente $(p<0,05)$ em relação à testemunha. 


\section{POVEDA PARRA, MOREIRA, FURLAN, CARVALHO, PEÑUELA SIERRA E FILHO}

A análise econômica (tabela III) indicou aumento linear $(\mathrm{p}<0,05)$ para o custo em ração por quilograma de peso vivo ganho (CR) com a inclusão da LEV40, sendo evidente o maior custo $(40,14 \%)$ ou menor índice de eficiência econômica $(71,36 \%)$ para o maior nível de inclusão. O teste de Dunnett cuja finalidade é comparar cada nível de inclusão $(5,10,15$ e $20 \%)$ com o nível $0 \%$, indicou que o CR para o nível $20 \%$ de inclusão de LEV40 é maior que o nível $0 \%$. Esta resposta pode ter ocorrido em função da adição de aminoácidos sintéticos, principalmente DL-metionina e Ltriptofano (tabela I), que elevaram o custo da ração, portanto, a decisão pela utilização da LEV40 vai depender da relação de preços existentes entre os ingredientes (milho, farelo de soja e a LEV40).

No segundo ensaio de desempenho (ensaio II), não houve interação $(p>0,05)$ dos níveis de inclusão da LEV40 e as formas da ração (farelada e peletizada) (tabela IV).
Da mesma forma, não foram observados efeitos $(p>0,05)$ do fator nível de inclusão da LEV40 nas rações para leitões. A peletização, independente do nível de levedura, proporcionou maior ganho diário de peso $(p<0,05)$ e melhorou a conversão alimentar. Era esperada melhoria no desempenho de suínos alimentados com a ração peletizada uma vez que o processo de peletização das dietas melhora a digestibilidade dos nutrientes pela ação mecânica, temperatura e umidade utilizada no processo (Andriguetto et al., 2000). A digestibilidade dos carboidratos aumenta, pois a peletização produz gelatinização parcialmente do amido e favorece a digestão da proteína (Wondra et al., 1995). Estes resultados são semelhantes aos observados por Moreira et al. (1999) que avaliando a levedura de recuperação seca por spray-dry em rações fareladas ou peletizadas para leitões na fase inicial e Costa et al. (2006) que avaliou diferentes formas físicas da ração de leitões não

Tabela IV. Desempenho de leitões dos 15 a $30 \mathrm{~kg}$ alimentados com dietas contendo levedura mista spray-dry (LEV40) e duas formas (farelada e peletizada) - ensaio II. (Performance of piglets from 15 to $30 \mathrm{~kg}$ fed diets containing mixed spray dry yeast (LEV40) and two forms (meal and pellet) - assay II).

\begin{tabular}{|c|c|c|c|c|c|c|c|}
\hline & \multicolumn{5}{|c|}{ Níveis de inclusão da LEV40 (\%) } & \multirow[b]{2}{*}{ Média $^{1}$} & \multirow[b]{2}{*}{ CV } \\
\hline & 0 & 5 & 10 & 15 & 20 & & \\
\hline \multicolumn{8}{|c|}{ Consumo diário de ração $(\mathrm{kg})$} \\
\hline \multicolumn{8}{|l|}{ Forma } \\
\hline Farelada & 1,23 & 1,15 & 1,12 & 1,16 & 1,11 & 1,15 & - \\
\hline Peletizada & 1,13 & 1,06 & 0,96 & 1,27 & 1,14 & 1,12 & - \\
\hline Média & 1,18 & 1,10 & 1,04 & 1,22 & 1,13 & 1,14 & 11,96 \\
\hline \multicolumn{8}{|c|}{ Ganho diário de peso $(\mathrm{kg})$} \\
\hline Farelada & 0,637 & 0,580 & 0,558 & 0,548 & 0,503 & $0,565^{B}$ & - \\
\hline Peletizada & 0,619 & 0,573 & 0,607 & 0,703 & 0,621 & $0,624^{A}$ & - \\
\hline Média & 0,628 & 0,577 & 0,583 & 0,625 & 0,562 & 0,595 & 12,23 \\
\hline \multicolumn{8}{|c|}{ Conversão alimentar } \\
\hline Farelada & 1,93 & 1,99 & 2,01 & 2,13 & 2,22 & $2,06^{\mathrm{B}}$ & - \\
\hline Peletizada & 1,83 & 1,85 & 1,60 & 1,80 & 1,85 & $1,79^{A}$ & - \\
\hline Média & 1,88 & 1,92 & 1,81 & 1,97 & 2,04 & 1,93 & 9,64 \\
\hline
\end{tabular}

${ }^{1}$ Não houve interação $(p>0,05)$ entre níveis de inclusão de LEV40 e forma de ração. ABMédias seguidas de letras maiúsculas diferentes na coluna, diferem $(p<0,05)$ pelo teste $F$. 


\section{LEVEDURA MISTA SPRAY-DRYNA ALIMENTAÇÃO DELEITÕES}

Tabela $V$. Custo de ração por quilograma de peso vivo ganho, índice de eficiência econômica e índice de custo de leitões dos 15 a $30 \mathrm{~kg}$, alimentados com dietas contendo levedura mista spray-dry (LEV40) e duas formas (farelada e peletizada) - ensaio III). (Feed cost per kilogram body weight gain; economic efficiency index, IEE, and index cost rate, IC, of piglets from 15 to $30 \mathrm{~kg}$ fed diets containing mixed spray dry yeast LEV40).

\begin{tabular}{|c|c|c|c|c|c|c|c|c|}
\hline & \multicolumn{5}{|c|}{ Níveis de inclusão de LEV40 (\%) } & \multirow[b]{2}{*}{ CV } & \multirow[b]{2}{*}{ Dun } & \multirow[b]{2}{*}{ Reg } \\
\hline & 0 & 5 & 10 & 15 & 20 & & & \\
\hline \multicolumn{9}{|c|}{ Custo de ração ( $\mathrm{R} \$ / \mathrm{kg} \mathrm{PV}$ ganho) } \\
\hline \multicolumn{9}{|l|}{ Forma } \\
\hline Farelada & 1,24 & 1,31 & $1,37^{*}$ & $1,53^{*}$ & $1,71^{*}$ & 4,78 & 0,05 & $\mathrm{~L}=0,01$ \\
\hline Peletizada & 1,26 & 1,31 & 1,17 & $1,39^{\star}$ & $1,52^{*}$ & 12,83 & 0,05 & NS \\
\hline \multicolumn{9}{|c|}{ Índice de eficiência econômica } \\
\hline Farelada & 100,00 & 94,08 & 90,35 & 80,73 & 72,27 & - & - & - \\
\hline Peletizada & 92,60 & 89,14 & 100,00 & 84,25 & 77,24 & - & - & - \\
\hline \multicolumn{9}{|c|}{ Índice de custo } \\
\hline Farelada & 100,00 & 103,30 & 110,68 & 123,87 & 138,27 & - & - & - \\
\hline Peletizada & 108,00 & 112,18 & 3100 & 118,70 & 129,46 & - & - & - \\
\hline
\end{tabular}

Dunn= Teste de Dunnet; $R$ eg= Análise de regressão; $L=$ Efeito linear forma farelada: $C R=1,19884+$ $0,0233166 X$. *Valor diferente $(p<0,05)$ em relação a testemunha.

observaram diferenças no desempenho dos leitões utilizando rações fareladas ou peletizadas.

Os resultados da análise econômica (tabela V) mostraram aumento linear $(\mathrm{p}<0,05)$ do custo de ração por quilograma de peso vivo com cada nível de inclusão da LEV40 para a ração farelada o que não aconteceu com a ração peletizada. O teste de Dunnett indicou que os níveis 10,15 e $20 \%$ de inclusão da LEV40 na ração farelada apresentaram custo superior $(10,68 ; 23,87$ e $38,27 \%$, respectivamente) quando comparado ao nível $0 \%$. Entretanto, para a forma peletizada os níveis que apresentaram maior custo por quilograma de ração de peso vivo foram os níveis 15 e $20 \%$ (18,70 e 29,46\%, respectivamente), o que pode ter sido em função da adição de aminoácidos sintéticos nestas rações. Portanto, a utilização da LEV40 na fase inicial na forma farelada ou peletizada, em níveis de até $20 \%$ não prejudicam o desempenho dos leitões, porém, eleva os custos da alimentação entre 38 e $29 \%$, respectivamente.

\section{CONCLUSÕES}

Os coeficientes de digestibilidade da levedura mista (cerveja + cana-de-açúcar) spray-dry (LEV40) são melhores que os da cana-de-açúcar (LEV35) para leitões na fase inicial. Os valores de ED $(\mathrm{kcal} / \mathrm{kg})$ da LEV35 e LEV40 são de 2788 e 3455 e de EM kcal $/ \mathrm{kg}$ de 2761 e 3289, respectivamente. A peletização das rações, independente do nível da LEV40, melhora o desempenho dos leitões. Dependendo da relação de preços entre os ingredientes, a inclusão da LEV40 pode ser inviável economicamente, como ocorreu neste estudo.

\section{AGRADECIMENTOS}

À BIOVALE, pela doação das leveduras utilizadas, bem como à CAPES e ao CNPq, pela concessão de bolsas de estudo. 


\section{POVEDA PARRA, MOREIRA, FURLAN, CARVALHO, PEÑUELA SIERRA E FILHO}

\section{BIBLIOGRAFIA}

Albuquerque, D.M.N.; Lopes, J.B.; Klein Jr., M.H. e Merval, R.R. 2011. Resíduo desidratado de cervejaria para suínos em terminação. Arq Bras Med Vet Zoo, 63: 465-472.

Andriguetto, J.M.; Perly, L.; Minardi, I.; Flemming, J.S.; Vinne, J.U.; Flemming, R.; Souza, G.A.; Andriguetto, J.L.; Dutra, M.J. e Steifert, C.R. 2000. Normas e padrões de nutrição e alimentação animal: Revisão 84 Nutrição. Editora DTPA-SDR-MAARA. Curitiba. 145 pp.

Araujo, L.F.; Junqueira, O.M. e Lopes, E.L. 2006. Utilização da levedura desidratada (Saccharomyces cerevisiae) para leitões na fase inicial. Cienc Rural, 36: 1576-1581.

Bellaver, C.; Fialho, E.T.; Protas, J.F.S. e Gomes, P.C. 1985. Radícula de malte na alimentação de suínos em crescimento e terminação. Pesqui Agropecu Bras, 20: 967-974.

Bertol, T.M.; Ludke, J.V. e Mores, N. 2000. Efeito de diferentes fontes protéicas sobre o desempenho, composição corporal e morfologia intestinal em leitões. Rev Bras Zootecn, 39: 1735-1742.

Brum, P.A.R.; Lima, G.J.M.M.; Zanotto, D.L. e Klein C.H. 1999. Composição nutritiva de ingredientes para rações de aves (Comunicado Técnico 241). EMBRAPA-CNPSA. Concórdia. 4 pp.

Cai, Y.; Zimmerman, D.R. and Ewan, R.C. 1994. Diurnal variation in concentrations of plasma urea nitrogen and amino acids in pigs given free access to feed or fed twice daily. J Nutr, 124: 1088-1093.

Castillo, W.; Kronka, R.N.; Pizauro Jr, M.C. e Carvalho, L.E. 2004. Efeito da substituição do farelo de soja pela levedura (Saccharomyces cerevisiae) desidratada como fonte protéica em dietas para leitões desmamados sobre peso de órgãos digestivos e atividade das enzimas pancreáticas. Arch Latinoam Prod Anim, 12: 12-20.

Costa, E.R.; Silva, L.P.G.; Silva, J.H.V.; Carvalho, L.E. e Carvalho, M.X.C. 2006. Desempenho de leitões alimentados com diversas formas físicas da ração. Cienc Anim Bras, 7: 241-247.

Furuya, W.M.; Seron, S.; Vargas, L.; Hayashi, C.; Furuya, V.R.B. e Soares, C.M. 2000. Níveis de levedura desidratada spray dried na dieta de alevinos revertidos de tilápia do Nilo (Oreochro- mis niloticus). Cienc Rural, 30: 699-704.

Generoso, R.A.R.; Gomes, P.C.; Rostagno, H.S.; Albino, F.T.; Barreto, S.L.T. e Brumano, G. 2008. Composição química e energética de alguns alimentos para frangos de corte em duas idades. Rev Bras Zootecn, 37: 1251-1256.

Gomes, M.F.M.;Barbosa, H.P.; Fialho, E.T.; Ferreira, A.S. e Lima, G.J.M.M. 1991. Análise econômica da utilização de triguilho para suínos (Comunicado Técnico, 179). EMBRAPA-CNPSA. Concórdia. 2 pp.

Junqueira, O.M.; Silz, L.Z.T.; Araújo, L.F.; Pereira A.A.; Laurentiz, A.C. e Filardi, R.S. 2008. Avaliação de níveis e fontes de proteína na alimentação de leitões na fase inicial de crescimento. Rev Bras Zootecn, 37: 1622-1627.

Marsh, W.H.; Fingerhut, B. and Miller, H. 1965. Automated and manual direct methods for determination of the determination of blood urea. Clin Chem, 11: 624-627.

Matterson, L.D.; Potter, L.M.; Stutz, M.W. and Singsen, E.P. 1965. The metabolizable energy of feed ingredients for chickens. University of Connecticut. Agricultural Experiment Station. Storrs, Connecticut. Res Report, 7: 11-14.

Miyada, V.S.; Lavorenti, A. e Packer, I.U. 1992. A levedura seca como ingrediente de rações fareladas ou peletizadas de leitões em recria, Rev Bras Zootecn, 21: 439-447.

Moreira, I.; Rostagno, H.S.; Coelho, D.T. e Tafuri, M.L. 1994. Determinação dos coeficientes de digestibilidade, valores energéticos e índices de controle de qualidade do milho e da soja integral processados pelo calor. Rev Bras Zootecn, 23: 916-929.

Moreira, I.; Rostagno, H.S.; Silva, M.A. e Tafuri, M.L. 1995. Uso de ração farelada ou peletizada quando se utiliza milho pré-cozido na alimentação de leitões. Rev Bras Zootecn, 1: 100-107.

Moreira, I.; Andreotti, F.L.; Furlan, A.C.; Martins, E.N. e Scapinello, C. 1996. Níveis crescentes de levedura de recuperação (Saccharomyces spp.), seca pelo método spray-dry na alimentação de leitões. Reunião Anual da Sociedade Brasileira de Zootecnia, 33. Fortaleza. Anais... UFC. Fortaleza.

Moreira, I.; Andreotti, F.A.; Furlan, A.C.; Scapinello, C. e Martins, E.N. 1998. Viabilidade da utilização 


\section{LEVEDURA MISTA SPRAY-DRY NA ALIMENTAÇÃO DE LEITÕES}

da levedura de recuperação (Saccharomyces sp.), seca pelo método de spray dry, na alimentação de leitões em fase de creche Rev Bras Zootecn, 27: 319-324.

Moreira, I.; Zanutto, C.A.; Furlan, A.C.; Martins, E.N. e Scapinello, C. 1999. Utilização de levedura de recuperação (Saccharomyces sp.), seca por spray dry, em rações fareladas ou peletizadas para leitões na fase inicial. Acta Scient, 21: 711-716.

Moreira, I.; Marcos Júnior, M.; Furlan, A.C.; Patricio, V.M.I. e Oliveira, G.C. 2002. Uso da levedura seca por spray-dry como fonte protéica para suínos em crescimento e terminação. Rev Bras Zootecn, 31: 962-969.

Moreira, J.A.; Miyada, V.S.; Menten, J.F.M.; Butolo, E.A.F. e lafigliola, M.C. 1998. Uso de levedura desidratada como fonte de proteína para suínos em crescimento e terminação. Rev Bras Zootecn, 27: 1160-1167.

NRC. 1998. Nutrient requirements of swine. National Academy of Science. Washington. D.C. 190 pp.

Rostagno, H.S.; Albino, L.F.T.; Donzele, J.L.; Gomes, P.C.; Oliveira, R.F.; Lopes, D.C.; Ferreira, A.S. e Barreto S.L.T. 2005. Tabelas brasileiras para aves e suínos: composição de alimentos e exigências nutricionais. Ed. UFV. Viçosa, MG. $186 \mathrm{pp}$.

Sampaio, I.B.M. 1998. Estatística aplicada a experimentação animal. Universidade Federal de Minas Gerais. Belo Horizonte-MG. 221 pp.

Silva, D.J. e Queiroz, A.C. 2002. Análise de alimentos. Métodos químicos e biológicos. Ed. UFV. Viçosa. $235 \mathrm{pp}$.

Spark, M.; Paschertz, H. and Kamphues, J. 2005. Yeast (different sources and levels) as protein source in diets reared piglets: effects on protein digestibility and N-metabolism. J Anim Physiol Anim Nutr, 89: 184-188.

UFV. 1997. Sistema de analises estadisticas e genéticas-SAEG. Versão 7.1. Universidade Federal de Viçosa. Viçosa, MG. 150 pp.

Wondra, K.J.; Hancock, J.D.; Behnke, K.C.; Hines, R.H. and Stark, C.R. 1995. Effects of particle size and pelleting on growth performance, nutrient digestibility and stomach morphology in finishing pigs. J Anim Sci, 73: 757-763.

Yamada, E.A.; Alvim, I.D.; Santucci, M.C.C. e Sgarbieri, V.C. 2003. Composição centesimal e valor proteico de levedura residual da fermentação etanólica e seus derivados. Rev Nutrição, 16: 423-432.

Zanutto, C.A.; Moreira, I.; Furlan, A.C.; Scapinello, C. e Murakami, A.E. 1999. Utilização de levedura de recuperação (Saccharomyces sp.) seca por spray dry ou por rolo rotativo na alimentação de leitões na fase inicial. Acta Scient, 21: 705710. 